\title{
O ENSINO JURÍDICO RESSIGNIFICADO: AS ATIVIDADES ACADÊMICAS DE EXTENSÃO COMO MECANISMOS DE ACESSO À JUSTICA QUALITATIVO
}

\author{
Camila Silveira Stangherlin* \\ Fabiana Marion Spengler*" \\ Rafaela Matos Peixoto Schaefer
}

RESUMO: Esse trabalho objetiva examinar os principais aspectos das atividades acadêmicas de extensão, a partir das implementações inseridas pela Resolução CNE/CES n 7/2018, no intuito de identificar suas contribuições para uma formação jurídica alinhada aos preceitos de acesso à justiça. Assim, questiona-se: quais as potencialidades contributivas das atividades extensionistas para a formação de juristas aptos a garantir um acesso à justiça qualitativo aos cidadãos? O método de abordagem é o dedutivo, com levantamento de dados efetuados por fontes primárias e secundárias. A conclusão aponta que o acesso à justiça pode ser impulsionado por experiências interativas entre comunidade acadêmica e sociedade.

Palavras-chave: Autocomposição de conflitos. Ensino jurídico. Extensão. Formação jurídica.

\section{THE MEANING OF LEGAL EDUCATION: ACADEMIC ACTIVITIES OF EXTENSION AS MECHANISMS OF ACCESS TO QUALITATIVE JUSTICE}

ABSTRACT: This article aims to examine the main aspects of academic extension activities, from the implementations inserted by Resolution CNE / CES no 7/2018, in order to identify their contributions to a legal formation aligned with the precepts of access to justice. Thus, the question is: what are the contributory potential of extension activities for the training of jurists able to guarantee qualitative access to justice? The approach method is the deductive one, with data collection made by primary and secondary sources. The conclusion indicates that

\footnotetext{
* Doutoranda em Direito pela UNISC e bolsista PROSUC/CAPES; Mestra em Direito pela URI/Santo Ângelo; Especialista em Direito Processual Civil pela Uninter; Licenciada no Curso de Formação Pedagógica para Professores pelo Instituto Federal Farroupilha - IFFar; Integrante do Projeto de Extensão "A crise da jurisdição e a cultura da paz: a mediação como meio democrático, autônomo e consensuado de tratar conflitos"; Professora de Direito e Advogada. Endereço Postal: Rua José do Patrocínio, 438, Bairro Cândido, CEP 97450-000, Cacequi/RS. E-mail: camilastangherlin@ hotmail.com.

** Bolsista de Produtividade em Pesquisa do CNPq (Pq2). Pós-doutora em Direito pela Università degli Studi di Roma Tre, em Roma na Itália, com bolsa CNPq (PDE). Doutora em Direito pelo programa de Pós-Graduação stricto sensu da Universidade do Vale do Rio dos Sinos - UNISINOS - RS, mestre em Desenvolvimento Regional, com concentração na área Político Institucional da Universidade de Santa Cruz do Sul - UNISC - RS. Líder do Grupo de Pesquisa "Políticas Públicas no Tratamento dos Conflitos" certificado pelo CNPq, Coordenadora da Rede de Pesquisa em Direitos Humanos e Políticas Públicas - REDIHPP. Endereço Postal: Rua Borges de Medeiros, 76, Centro, CEP: 96810-034. Santa Cruz do Sul-RS. E-mail: fabiana@ unisc.br.

*** Mestranda em Direito junto ao Programa de Pós-Graduação da Universidade de Santa Cruz do Sul (UNISC), com bolsa/taxa Prosuc-Capes. Especialista em Direito Processual Civil pela Faculdade Futura/SP. Integrante do grupo de pesquisa denominado Políticas Públicas no Tratamento de Conflitos, vinculado ao CNPq e liderado pela Professora Pós-Doutora Fabiana Marion Spengler. Mediadora voluntária de família no Projeto de Extensão "A crise da jurisdição e a cultura da paz: a mediação como meio democrático, autônomo e consensuado de tratar conflitos" da UNISC, desenvolvido junto a Defensoria Pública de Santa Cruz do Sul. Advogada. Endereço Postal: Rua Reinoldo Schwantz, 41, Bairro Castelo Branco, CEP: 96835-284. Santa Cruz do Sul - RS. E-mail: rafaelapeixoto@mx2.unisc.br.
}

Revista de Pesquisa e Educação Jurídica | e-ISSN: 2525-9636 | Encontro Virtual | v. 6 | n. 2 | p. 01 - 19 | Jul/Dez. 2020. 
access to justice can be driven by interactive experiences between the academic community and society.

Keywords: Access to justice. Conflict self-composition. Extension. Legal education. Legal training.

\section{INTRODUÇÃO}

A forma como as Instituições de Ensino Superior - IES estão ofertando o ensino jurídico nos cursos de Direito vem sendo reformulada com o avanço natural da civilização. Ao passo que a sociedade apresenta contornos de uma nova realidade, com características que reforçam a complexidade vislumbrada nas relações sociais contemporâneas, também as instituições passam a adequar-se a esse novo panorama. Nesse aspecto, o Poder Público, por intermédio de seus órgãos apropriados, busca agir em consonância com as necessidades refletidas na vivência cotidiana, a fim de nortear um ensino que coadune com as múltiplas implicações da vida em comum, e, que forme profissionais aptos ao desempenho de suas atividades nesse transmutado cenário.

Nesse contexto, os futuros juristas, como sujeitos interlocutores entre a letra da Lei e a efetivação do direito fundamental de acesso à justiça, são figuras essenciais que necessitam compreender a problemática social e manter-se inseridos na realidade que os circunda. Apesar do processo de ensino e aprendizagem efetuar-se, basicamente, nos limites da sala de aula, sua aplicação precisa estar voltada para as constatações provenientes da comunidade em que se encontra. Sendo assim, as atividades acadêmicas de extensão, em virtude de suas diretrizes, tornam-se ferramentas oportunas para uma inter-relação entre o ambiente acadêmico e a prática profissional, não apenas como mecanismo de exercício prático, mas como instrumento capaz de despertar a dimensão do sentido de justiça.

Sendo assim, o presente trabalho tem por objetivo examinar os principais aspectos das atividades acadêmicas de extensão, a partir das implementações inseridas pela Resolução CNE/CES n 7/2018 (normativa que estabeleceu as diretrizes para a extensão na educação superior brasileira), no intuito de identificar suas contribuições para uma formação jurídica alinhada aos preceitos de acesso à justiça. Desse modo, o problema que move tal estudo questiona: quais as potencialidades contributivas das atividades extensionistas para a formação de juristas aptos a garantir um acesso à justiça qualitativo aos cidadãos? Para o deslinde da pesquisa será utilizado o método de abordagem dedutivo, com levantamento de dados realizado através de pesquisa bibliográfica e pesquisa documental. O método de 
procedimento é o monográfico, tratando-se de uma pesquisa exploratória, segundo a classificação relacionada ao seu objetivo.

Primeiramente, o artigo abordará os novos aspectos relacionados à educação jurídica, introduzidos pela Resolução CNE/CES n 5/2018, que trouxe novas diretrizes aos cursos de Direito do país, sobretudo, aqueles referentes a um ensino mais humanizado e mais próximo à comunidade externa. Ainda, de forma geral, será examinada efetivação do acesso à justiça por vias consensuais e autônomas, como a mediação e a conciliação, que podem ser impulsionadas pelas interações dialógicas estabelecidas entre conflitantes e juristas (formados e/ou em formação).

Por conseguinte, será analisada as principais vertentes de formação dos profissionais de Direito, destacando-se desde o processo de ensino e aprendizagem fortemente abarcado nos preceitos legais, dogmáticos e positivistas, até a inserção de práticas extensionistas. Finalmente, o trabalho se voltará à compreensão das atividades acadêmicas de extensão, averiguando as potencialidades dessas práticas na construção de profissionais jurídicos comprometidos com a concretização do direito de acesso à justiça.

Por longo período o acesso à jurisdição foi entendido como suficiente na efetivação do direito fundamental de acesso à justiça, o que contribuiu para manutenção de cursos de Direito estruturados na ótica litigante dos procedimentos contenciosos. Contudo, como consequência de diversas pesquisas sobre tema (como o Projeto Florença, coordenado por Mauro Cappelletti, por exemplo), assim como, por meio de políticas públicas relacionadas ao assunto (como a Resolução $n^{\circ}$ 125/2010, do Conselho Nacional de Justiça), percebe-se uma ressignificação que necessita ser implantada no âmbito de formação e preparação para o exercício das atividades jurídicas. Nesse aspecto, a partir das inovações na seara educacional, como a obrigatoriedade das atividades de extensão nas matrizes curriculares, tem-se a possibilidade de ampliar os mecanismos que aproximam o universo jurídico da órbita social, o que pode ser fundamental na edificação de posturas profissionais mais adequadas ao contexto social hodierno.

\section{O ENSINO JURÍDICO CONTEMPORÂNEO: ANTIGOS E NOVOS CONTORNOS}


Desde a instalação dos primeiros cursos de Direito no Brasil ${ }^{1}$, ainda no período imperial, até a conjuntura atual, muitas transformações nessa área foram apercebidas. Os próprios objetivos entorno da conquista do grau de bacharelado sofreram alteração: frente às características políticas e sociais da época, a ascensão de poder era impelida pela "formação científica, principalmente, nos cursos de Direito" (ANDREUCCI; MAILLART, 2013, p. 66).

Sofrendo influência do contexto europeu, e, arraigado ao Direito Romano e ao Direito Canônico, os primeiros cursos de Direito ostentavam um enfoque estritamente dogmático e tecnicista. O perfil profissional almejado voltava-se, claramente, à formação de operadores de Direito, ou seja, sujeitos hábeis às questões de práticas jurídicas, com um conhecimento que suprisse às necessidades pontuais burocráticas de um mercado de trabalho em plena expansão. Sob compreensões objetivas, o viés pedagógico e científico foi sendo contraposto, de tal sorte que a produção intelectual não ordenava prioridade, e, tampouco eram oportunizados ambientes de debates, pesquisas científicas e produções acadêmicas.

A busca pelo conhecimento técnico encontrava respaldo no modo segmentado do pensamento jurídico, que, aliado ao isolamento de outras áreas de conhecimento, impulsionava o perfil de uma formação profissional pouco integralizada, limitando interrelações e contribuindo para um posicionamento insular de juristas. Nesse sentido, "a racionalidade do Direito passou a estar ligada a uma noção de Estado forte, soberano e de norma jurídica hierarquizada" (COSTA; ROCHA, 2018, p. 35), o que, por um lado, era sustentáculo para a requisitada perspectiva de segurança das relações jurídicas, mas por outro, desconstituía os estudantes para as vicissitudes de uma sociedade em mudanças constantes e cada vez mais complexas.

Por meio desse olhar histórico, e, em termos de processo de ensino jurídico, pode-se compreender que poucas modificações foram constatadas desde o período inaugural. O local do saber retrata um verdadeiro replicar de ideias prontas e de dogmas reverberados. Ainda se vislumbra, em significativa parte dos $\operatorname{cursos}^{2}$, matrizes curriculares com componentes semelhantes àqueles das faculdades de Direito existentes em período anterior à redemocratização do país. A ideia inicial de segregação na aprendizagem, em que cada

\footnotetext{
${ }^{1}$ As primeiras faculdades de Direito do Brasil foram inauguradas em São Paulo e em Olinda - posteriormente transferida para Recife, em 1827, sendo tal monopólio do ensino jurídico "quebrado em 1879, com o Decreto $\mathrm{n}^{\circ}$ 7.247, de 19 de abril" (NEDER,2018, p. 121).

${ }_{2}^{2}$ Sobre o tema, sugere-se a leitura disponível em: https://www.unirios.edu.br/revistarios/media/ revistas/2018/19/a_atual_formacao_academica_dos_profissionais_de_direito_e_a_justica_consensual.pdf.
} 
professor ministra suas aulas de forma fechada, com pequena (ou nenhuma) comunicação com as demais, ainda paira as estruturas de formação de juristas na contemporaneidade.

De forma geral, as disciplinas ofertadas configuram vias objetivas para um conhecimento robotizado capaz de permitir uma ascensão profissional, em que o aprendizado humanístico e a conectividade com o tecido social parecem estar em segundo plano. Ao se focalizar em "bibliografias baseadas em grandes manuais técnicos, esquematizados, os quais não trazem reflexões a respeito dos temas estudados" (DENARDI; FLORÊNCIO FILHO, 2017, p. 104), acaba-se por sujeitar os discentes à aquisição do conhecimento infecundo, com foco na ordem e na afirmação.

No entanto, não se pode olvidar que, com os avanços e conquistas atinentes aos direitos humanos e garantias fundamentais dos cidadãos, chegou-se a uma educação com viés emancipatório, com perspectivas mais igualitárias, tendo no processo de ensino, a instrumentalidade de uma sociedade mais justa. Essa reflexão, também alcançou a seara jurídica, porém, percorreu caminhos diferentes, de maneira que ainda reverbera nos bancos acadêmicos resquícios de um ensino elitista, impositivo, autoritário.

Os caminhos percorridos pela educação jurídica, visando uma reformulação das diretrizes de ensino, decorre de uma instalada crise no sistema de prestação jurisdicional brasileiro. Conforme destacado por José Luis Bolzan de Morais e Fabiana Marion Spengler (2019, p. 41-42), “é fato que o Judiciário viu sua estrutura (física, política, pessoal...) tornar-se inadequada diante dos avanços da sociedade moderna, sem o necessário acompanhamento em termos tecnológicos, administrativos e comportamentais". Cada fração que compõe esse sistema incongruente frente aos anseios sociais atuais é formada por sujeitos provenientes dos bancos acadêmicos.

Sendo assim, essa percepção da educação jurídica sob o aspecto quantitativo e, por vezes, automatizado na reprodução de conteúdos - alinhada mais à forma, ao rito e aos requisitos procedimentais do que à satisfação do cidadão/jurisdicionado - fez irromper a ideia de uma necessária revisão e readequação do ensino, de forma que os juristas em atuação possam compreender, ainda na fase de formação, o quão essencial é a prática profissional centrada no cidadão para a disponibilidade de um acesso à justiça efetivo.

Nesse aspecto, determinadas reformas passaram a ser implementadas em decorrência dos avanços dos estudos relacionados aos instrumentos jurisdicionais, no intuito de "tornar a assistência jurídica de alta qualidade acessível a todos" (CAPPELLETTI; GARTH, 1988, p. 
143). Não só os métodos utilizados para a resolução de conflitos ou a estrutura judiciária foram questionados, mas todos os aspectos que permeiam a profissão jurídica, desde a formação até a prática. Embora essenciais para muitos casos, os procedimentos contenciosos e dependentes de uma decisão impositiva não são suficientes para suprir necessidades atreladas aos relacionamentos do âmbito familiar, envoltos em fatores emocionais, por exemplo.

De igual maneira, as decisões típicas da seara judicial tomam por foco os aspectos objetivos contidos nos ritos processuais, desconsiderando certas peculiaridades como os sentimentos das partes envolvidas, ou as necessidades de fala e de escuta, elementos imprescindíveis para que certos conflitos obtenham mais do que uma solução, mas um tratamento. Como frisam José Luis Bolzan de Morais e Fabiana Marion Spengler (2019), por vezes o Direito, assim como alguns remédios, tem enfoque nos sintomas, e não nas causas do mal-estar.

Na compreensão dessa heterogeneidade das relações conflitivas, e, no afã de tornar os serviços jurídicos mais eficazes, as experiências positivas desenvolvidas extrajudicialmente foram, paulatinamente, sendo introduzidas no universo jurídico. Sobre o tema, Stangherlin e Spengler (2019, p. 184) destacam que, "no revés de se efetivar a impulsão da descentralização de mecanismos que visam à pacificação das relações sociais [...], o Estado empenhou-se em emoldurar às suas normativas os meios de tratamento de conflitos que estavam se popularizando em profusão".

A Resolução $n^{\circ}$ 125/2010, do Conselho Nacional de Justiça, enquanto política pública, concretizou-se como um marco no tema de acesso à justiça, instituindo o tratamento adequado dos conflitos de interesses no âmbito do Poder Judiciário, como a prática da mediação e da conciliação - o que, mais tarde, resultou nos diplomas legais atuais que tratam do assunto. A partir de tais disposições no ordenamento jurídico, cuidou-se também de incluir o debate no cerne de formação jurídica, prevendo o art. 6º inc. V, da Resolução nº 125/2010, que, visando o incentivo à autocomposição e à pacificação social, o CNJ deve:

\footnotetext{
V - buscar a cooperação dos órgãos públicos competentes e das instituições públicas e privadas da área de ensino, para a criação de disciplinas que propiciem o surgimento da cultura da solução pacífica dos conflitos, bem como que, nas Escolas de Magistratura, haja módulo voltado aos métodos consensuais de solução de conflitos, no curso de iniciação funcional e no curso de aperfeiçoamento;
} 
Sendo assim, o debate entorno do acesso à justiça viu-se ampliado nos cursos jurídicos, em muitos casos, com a criação de disciplinas específicas abordando o tema. Não só o ensino teórico, como o ensino prático, foi afetado pelas ondas difundidas por Cappelletti e Garth (1988). Formas autocompositivas, como a conciliação e a mediação, ou, de heterocomposição, como a arbitragem, receberam, nos últimos anos, um novo olhar, sendo reflexo do entendimento de que o direito fundamental de acesso à justiça insculpido na Constituição Federal de $1988^{3}$ não se perfaz pelo simples acesso aos serviços ofertados pelo Poder Judiciário para que o cidadão receba uma decisão que torne resoluto o seu conflito.

Nesse contexto, convém ressaltar os principais aspectos relacionados aos mecanismos alternativos e/ou complementares à convencional decisão adjudicada, que dispõem de meios autônomos, consensuais e dialogados para alcançar uma resposta satisfatória aos envolvidos, e, portanto, requerem profissionais que compreendam suas vertentes.

\subsection{O ACESSO À JUSTIÇA POR VIAS DIFERENCIADAS}

Diante de uma sociedade reconhecidamente litigiosa ${ }^{4}$, a inserção cultural de novas formas de efetuar o acesso à justiça não é tarefa simples. Em que pese as diretivas oriundas do poder público, como as resoluções que serão adiante estudadas, torna-se fundamental uma abordagem educacional que contemple a percepção ampla e completa de acesso à justiça. $\mathrm{Ou}$ seja, não é suficiente a propagação de um ensino estritamente processual, uma vez que "o processo tende a perder a conotação participativa, assumindo um procedimento de elevado conteúdo técnico, burocrático e formalista" (SPENGLER, 2016, p. 200). Embora suficiente para determinadas relações, boa parte dos conflitos requer uma comunicação bilateral que possibilite a reconstrução histórica dos acontecimentos e, então, o consequente entendimento mútuo.

\footnotetext{
${ }^{3}$ Conforme dispõe a CF/88, o acesso à justiça é um direito fundamental previsto no artigo $5^{\circ}$, inciso XXXV, que prevê que "a lei não excluirá da apreciação do Poder Judiciário lesão ou ameaça a direito". Este direito garante a todos e a todas mais do que a possibilidade de acesso às vias do Poder Judiciário, o acesso à Justiça. Dessa maneira, é dever do Estado, por meio de ações específicas, garantir os meios adequados para que tal preceito se efetive.

${ }^{4}$ O relatório anual Justiça em Números, do Conselho Nacional de Justiça, retrata os índices de litigiosidade do país. Os últimos resultados podem ser acessados em: https://www.cnj.jus.br/pesquisas-judiciarias/justica-emnumeros/.
}

Revista de Pesquisa e Educação Jurídica | e-ISSN: 2525-9636 | Encontro Virtual | v. 6 | n. 2 | p. 01 - 19 | Jul/Dez. 2020. 
Nesse sentido, o que Mauro Cappelletti e Bryant Garth (1988) chamaram de justiça coexistencial, como os mecanismos de autocomposição ${ }^{5}$ de conflitos, tende a oferecer elementos para que os conflitantes possam dialogar, reavaliar posturas, desenvolver sentimentos empáticos, reconhecer a visão do outro e alcançar o consenso. A busca por soluções/tratamentos de conflitos por intermédio de instrumentos que aproximam as partes, colocando-as em condições convergentes - e não opostas - é um dos preceitos de métodos como a conciliação e a mediação: substitui-se causas competitivas, por causas cooperativas.

Conforme aduz a autora Fernanda Tartuce (2008, p. 201) a adoção de práticas autocompositivas, como a conciliação e a mediação, é uma tendência percebida em âmbito mundial, onde o estimulo se dá "não só em virtude dos problemas dos sistemas jurídicos e judiciários vigentes, mas também pela evolução da sociedade rumo a uma cultura participativa, em que o cidadão seja protagonista da busca da solução por meio do diálogo e do consenso".

A conciliação, apesar de já estar inserida judicialmente a mais tempo (a Lei $\mathrm{n}^{\circ}$ 9.099/1995, que trata dos juizados especiais, desenvolve a conciliação), teve seu contexto ampliado, ressaltando os benefícios por trás de espaços que fomentam a construção de um acordo entre as partes. Nessa perspectiva, o atual Código de Processo Civil (Lei $\mathrm{n}^{\circ}$ 13.105/2015) prevê o estímulo da conciliação, da mediação e de outros métodos de solução consensual por parte dos profissionais jurídicos (art. $3^{\circ}, \S 3^{\circ}$ ), sendo necessário, porém, não os tratar como sinônimos.

Conforme destacado por Petrônio Calmon (2019, p. 140), a conciliação difere da mediação em significativos aspectos, especialmente no fato de que "o conciliador manifesta sua opinião sobre a solução justa para o conflito e propõe os termos do acordo". Ademais, a doutrina costuma indicar a prática da conciliação para relações interpessoais que não envolvam vínculos emocionais, como as relações consumeristas, contratuais, ou até mesmo trabalhistas, dentro dos limites legais cabíveis.

Já o instituto da mediação volta-se aos relacionamentos mais complexos, envoltos por sentimentos divergentes que levaram ao rompimento da relação interpessoal. Sua inserção no ordenamento jurídico pátrio deu-se recentemente, pela edição da Lei no 13.140/2015. Até então, essas atividades eram desenvolvidas em seara extrajudicial, sobretudo, comunitária,

\footnotetext{
${ }^{5}$ Diferentemente da heterocomposição, onde as partes acatam a decisão impositiva de uma terceira figura, na autocomposição as partes, geralmente com o auxílio de um terceiro facilitador (mediador ou conciliador), chegam comumente em um acordo que melhor atenda aos interesses suscitados.
} 
onde fora genuinamente edificada. Ainda, em experiências judiciais, com o incentivo de juristas que já acreditavam na potencialidade das sessões de mediação para o deslinde de determinados litígios, as práticas foram pouco a pouco ganhando espaço ${ }^{6}$.

Importa frisar que o papel do mediador, ao contrário do conciliador, não está em privilegiar o acordo. Sua função perpassa pela condução das partes ao diálogo colaborativo, à escuta pacífica - que tem o intuito de compreender o outro, e não de afrontá-lo - ao restabelecimento da comunicação. Nessas condições, o acordo irrompe-se como consequência. Como assevera Fabiana Marion Spengler (2017, p. 8-9):

O tratamento do conflito através da mediação pode acontecer mediante uma pluralidade de técnicas que vão da negociação à terapia. Os contextos nos quais é possível aplicá-la são vários: mediação judicial e extrajudicial, no Direito do Trabalho, no Direito Familiar, mediação comunitária, escolar, dentre outros. Possuem como base o princípio de religar aquilo que se rompeu, restabelecendo uma relação para, na continuidade, tratar o conflito que deu origem ao rompimento.

Tratando o lado oculto, subjetivo do conflito, ou, construindo um acordo com a participação dos próprios envolvidos, a mediação e a conciliação são formas eficazes de acesso à justiça. Outros mecanismos também são destaque como vias alternativas à jurisdição estatal convencional, como a negociação ou a arbitragem, entretanto, na autocomposição que engloba a presença de um facilitador, pontos essenciais para a restauração de uma relação social pacífica são trabalhados. Ademais, nos espaços em que o diálogo é priorizado, assim como as decisões conjuntas, "há o caráter de inclusão social; há o fomento ao exercício da cidadania; há o anseio pela democratização do acesso à justiça; há a busca pela pacificação social, e tantas outras respostas voltadas aos óbices que afastam o cidadão do sentimento de justiça” (STANGHERLIN, SPENGLER, 2018, p. 84).

Sob essa perspectiva, não cabe mais um ensinamento jurídico tão somente focalizado nas disputas processuais. É tempo de readequação e de ressignificação do exercício profissional do jurista. O acesso à justiça, não só pode, como deve ser ofertado de uma maneira mais horizontalizada, incluindo o cidadão e aproximando sujeitos até então antagônicos (não só os conflitantes, mas os profissionais e os jurisdicionados). Por tal razão, o período de formação em Direito configura um elemento diferencial, capaz de preparar

\footnotetext{
${ }^{6}$ Sobre o tema, sugere-se a leitura de: GROSMAN, Claudia Frankel; MANDELBAUM, Helena Gurfinkel. Mediação no Judiciário: teoria na prática, prática na Teoria. São Paulo: Primavera Editorial, 2011.
} 
indivíduos para ações singulares, mas também para atividades voltadas à coletividade, à pluralidade, ao bem comum.

\section{O PROFISSIONAL JURÍDICO EM FORMAÇÃO: AS DIRETRIZES ATUAIS}

Por longos anos o ensino vislumbrado nos cursos de Direito do país tem mantido um posicionamento formal e tradicional que arrimou o processo de ensino e aprendizagem em conceitos, dogmas, códigos e observância estritamente positivista. Essa postura propiciou a formação de verdadeiros "técnicos jurídicos", habilitados em cumprir com os ditames da letra da lei. Entrementes, como já destacado, a transmutabilidade social fez transparecer a insuficiência de apreciações obsoletas para os anseios de inter-relações multiformes. Nesse contexto, como bem observa Michel Serres (2018, p. 82), “a complexidade não desaparece! Ela cresce e continuará crescendo, pois todos se aproveitam do conforto e da liberdade que vem embutida; ela caracteriza a democracia".

Sendo assim, oportunizar respostas adequadas às distintas modalidades de conflitos que adentram a órbita jurídica é função do Estado, como garantidor de um acesso à justiça qualitativo aos seus cidadãos. De igual maneira, a formação dos profissionais responsáveis por dar concretude aos direitos e garantias, configura fator essencial a ser considerado pelos órgãos públicos incumbidos dessa contemplação. Com o avanço das políticas públicas direcionadas ao tratamento adequado dos conflitos de interesse em âmbito judiciário, esse tema também precisou adentrar a seara da educação jurídica. Dessa forma, a Resolução $\mathrm{CNE} / \mathrm{CES} \mathrm{n} \mathrm{n}^{\circ} 5$, de 18 de dezembro de $2018^{7}$, que instituiu as recentes diretrizes para os cursos de Direito, cuidou de determinar novos elementos estruturais para a formação desses profissional, visando o desenvolvimento de competências cognitivas, instrumentais e interpessoais.

\footnotetext{
${ }^{7}$ De acordo com o art. $1^{\circ}$, o conteúdo da Resolução CNE/CES n ${ }^{\circ} 5$ "institui as Diretrizes Curriculares Nacionais do curso de graduação em Direito, bacharelado, a serem observadas pelas Instituições de Educação Superior (IES)". Trata-se de documento assinado por Antonio de Araújo Freitas Júnior, Presidente da Câmara de Educação Superior do Conselho Nacional de Educação, no uso de suas atribuições legais, com fundamento no art. 9o, § 2o, alínea "e", da Lei no 4.024, de 20 de dezembro de 1961, com a redação dada pela Lei no 9.131, de 25 de novembro de 1995, e as Diretrizes Curriculares Nacionais elaboradas pela Câmara Consultiva Temática de Política Regulatória do Ensino Jurídico, propostas ao CNE pela Secretaria de Regulação e Supervisão da Educação Superior do Ministério da Educação (SERES/MEC), e com fundamento no Parecer CNE/CES no 635/2018, homologado pela Portaria MEC no 1.351, de 14 de dezembro de 2018.
} 
Dentre as readaptações apresentadas pelo conteúdo normativo, alguns pontos merecem destaque, especialmente, aqueles relacionados à ressignificação do acesso à justiça. Nesse aspecto, a Resolução CNE/CES n ${ }^{\circ}$ 5/2018 acrescentou no rol de conteúdos necessários para a formação técnico-jurídica do bacharel em Direito, o estudo das formas consensuais de solução de conflitos, tal como preconizado pela Resolução n ${ }^{\circ}$ 125/2010, do CNJ. Eis um significativo avanço para o campo das disciplinas que, comumente, figuravam na lista de componentes eletivos/optativos, e, eventualmente, restavam desacompanhadas de um viés pedagógico capaz de implementar uma reconstrução da tradicional visão litigante do bacharelando.

Ainda, as atuais diretrizes introduziram no decorrer do seu texto expressões atinentes à relevância da diversidade sociocultural, da interdisciplinaridade, do pluralismo contemporâneo, e da importante preparação acadêmica para a solução de conflitos arrimada no diálogo e na autonomia dos envolvidos, como pode ser constatado:

\begin{abstract}
Art. 3 O curso de graduação em Direito deverá assegurar, no perfil do graduando, sólida formação geral, humanística, capacidade de análise, domínio de conceitos e da terminologia jurídica, capacidade de argumentação, interpretação e valorização dos fenômenos jurídicos e sociais, além do domínio das formas consensuais de composição de conflitos, aliado a uma postura reflexiva e de visão crítica que fomente a capacidade e a aptidão para a aprendizagem, autônoma e dinâmica, indispensável ao exercício do Direito, à prestação da justiça e ao desenvolvimento da cidadania.
\end{abstract}

Em direção similar, o artigo $4^{\circ}$ enfatiza a essencialidade de posturas educativas que possibilitem o ensino e a aprendizagem também imergidos na área interpessoal (e não estritamente na área cognitiva), sendo essa propulsora de uma cultura pacifista:

\footnotetext{
Art. $4^{\circ} \mathrm{O}$ curso de graduação em Direito deverá possibilitar a formação profissional que revele, pelo menos, as competências cognitivas, instrumentais e interpessoais, que capacitem o graduando a:

[...]

VI - desenvolver a cultura do diálogo e o uso de meios consensuais de solução de conflitos;
}

Assim, integralizando os tópicos anteriores, o artigo $5^{\circ}$ frisa o teor de obrigatoriedade das disciplinas autocompositivas, de maneira que os Projetos Pedagógicos dos Cursos de Direito devem adequar seus conteúdos de forma a incluir o ensino que abarque as formas consensuais de solução de conflitos. 
Art. $5^{\circ} \mathrm{O}$ curso de graduação em Direito, priorizando a interdisciplinaridade e a articulação de saberes, deverá incluir no PPC, conteúdos e atividades que atendam as seguintes perspectivas formativas:

[...]

II - Formação técnico-jurídica, que abrange, além do enfoque dogmático, o conhecimento e a aplicação, observadas as peculiaridades dos diversos ramos do Direito, de qualquer natureza, estudados sistematicamente e contextualizados segundo a sua evolução e aplicação às mudanças sociais, econômicas, políticas e culturais do Brasil e suas relações internacionais, incluindo-se, necessariamente, dentre outros condizentes com o PPC, conteúdos essenciais referentes às áreas de Teoria do Direito, Direito Constitucional, Direito Administrativo, Direito Tributário, Direito Penal, Direito Civil, Direito Empresarial, Direito do Trabalho, Direito Internacional, Direito Processual; Direito Previdenciário, Formas Consensuais de Solução de Conflitos;

Importa ainda ressaltar que tamanhas alterações devem ser implementadas pelas instituições de ensino conforme o prazo estabelecido pelo art. 14 (prazo máximo de até dois anos aos alunos ingressantes, a partir da data de publicação da Resolução).

De modo geral, pode-se perceber que as alterações efetivadas nas diretrizes dos cursos jurídicos indicam uma maior atenção à prática profissional que recepcione o cidadão como o cerne de seus serviços, reforçando, para tanto, a importância da interdisciplinaridade e da perspectiva formativa que incentive as competências interpessoais. Uma vez que as relações de trabalho, assim como as relações conflitivas que anseiam por justiça, são compostas por relacionamentos entre indivíduos distintos, pessoas de múltiplas características, a adequada preparação nessa área é base para a obtenção de serviços jurídicos consubstanciados no acesso à justiça.

$\mathrm{O}$ advento de um ato normativo indicando a necessidade de uma formação menos focada em procedimentos contenciosos reflete as conquistas de debates iniciados há largos anos, que enxergavam no ajustamento das matrizes curriculares jurídicas, condição indispensável para uma mudança paradigmática e cultural, em prol de uma sociedade mais pacífica e com menores índices de judicialização de conflitos. Todavia, é necessário atentar ao fato de que, por mais benéficas que sejam as propostas apresentadas pelo texto resolutivo, suas implicações não são suficientes para potencializar tal transição.

Nesse sentido, além de uma reestruturação atinente aos conteúdos e componentes curriculares mínimos de formação jurídica - em consonância com a política judiciária nacional - torna-se essencial dar solidificação à "interdisciplinaridade", prevista como um dos pilares do ensino jurídico atual. Sua definição é apontada pela doutrina como um encontro 
entre diferentes disciplinas, onde cada uma afirma suas ideias e conceitos, estabelecendo uma troca ou uma cooperação (MORIN, 2005). Ou seja, a interdisciplinaridade pode limitar-se a uma troca entre áreas de especialização, ou, pode estruturar-se como elo entre os saberes e os anseios da vida profissional. Justamente, em complementariedade, surge a ideia de articulação necessária entre atividades de pesquisa e de extensão, contempladas pelo art. $2^{\circ}$, § $3^{\circ}$, e pelo art. $7^{\circ}$, da Resolução CNE/CES nº 5/2018.

Nesse viés, as atividades acadêmicas de extensão requerem um olhar atento dentro do campo educativo, já que representam espaços próprios de aproximação dos futuros profissionais com a comunidade externa. Ademais, por intermédio de projetos ou clínicas, conforme mencionado pelo art. $7^{\mathbf{0}^{8}}$, pode-se impulsionar a prática de ações respaldadas na visão social e comunitária do Direito, reforçando a importância da conexão entre juristas e jurisdicionados para o alcance de um acesso à justiça qualitativo. Dessa forma, no intuito de verificar os aspectos principais das atividades extensionistas previstas para os cursos de Direito, um aprofundamento na análise de suas diretrizes se faz preciso, o que se propõe no próximo tópico.

\section{POTENCIALIDADES NA EXTENSÃO: CONSTRUINDO PONTES}

No mesmo momento em que foram apresentadas as novas diretrizes para os cursos de Direito do país, foram também instituídas as diretrizes para as atividades de extensão na educação superior brasileira, através de uma normativa subsequente: a Resolução CNE/CES $\mathrm{n}^{\mathrm{o}} 7$, de 18 de dezembro de 2018, que definiu princípios, fundamentos e procedimentos a serem observados pelas instituições de ensino superior de todos os sistemas de ensino do país.

Um dos destaques iniciais contidos em seu texto está no art. $3^{\circ}$, onde é referido o caráter integrativo das atividades de extensão junto à matriz curricular dos cursos e à organização da pesquisa, constituindo, assim, um processo interdisciplinar. De igual maneira, é ressaltado a busca pela promoção da interação entre as instituições de ensino superior e os outros setores da sociedade, o que se dá pela produção e aplicação do conhecimento.

\footnotetext{
8 Dispõe o art. $7^{\circ}$ da Resolução CNE/CES no 5/2018: Os cursos deverão estimular a realização de atividades curriculares de extensão ou de aproximação profissional que articulem o aprimoramento e a inovação de vivências relativas ao campo de formação, podendo, também, dar oportunidade de ações junto à comunidade ou de caráter social, tais como clínicas e projetos.
} 
Para que tais orientações não ficassem esparsas nas estruturas curriculares, e, tampouco discrepantes entre as instituições de ensino, o art. $4^{\circ}$ cuidou de especificar o quantitativo mínimo a ser destinado para ações extensionistas. Dessa forma, tem-se regulamentada a previsão de, no mínimo, $10 \%$ (dez por cento) do total da carga horária curricular estudantil dos cursos de graduação, a ser direcionada à prática de atividades de extensão (que, conforme art. $8^{\circ}$, podem ser na modalidade de programas, projetos, cursos e oficinas, eventos, ou, prestação de serviços).

Nesse viés, importante as coordenadas estabelecidas pela norma para que as práticas da extensão sigam um propósito comum. Nessa compreensão, o art. $5^{\circ}$ traz os fundamentos a serem considerados para que, independente da modalidade instituída, a base extensionista esteja arrimada na formação do estudante e no seu envolvimento com a comunidade externa:

\footnotetext{
Art. $5^{\circ}$ Estruturam a concepção e a prática das Diretrizes da Extensão na Educação Superior:

I - a interação dialógica da comunidade acadêmica com a sociedade por meio da troca de conhecimentos, da participação e do contato com as questões complexas contemporâneas presentes no contexto social;

II - a formação cidadã dos estudantes, marcada e constituída pela vivência dos seus conhecimentos, que, de modo interprofissional e interdisciplinar, seja valorizada e integrada à matriz curricular;

III - a produção de mudanças na própria instituição superior e nos demais setores da sociedade, a partir da construção e aplicação de conhecimentos, bem como por outras atividades acadêmicas e sociais;

IV - a articulação entre ensino/extensão/pesquisa, ancorada em processo pedagógico único, interdisciplinar, político educacional, cultural, científico e tecnológico.
}

De igual maneira, na seara de formação do profissional jurídico não cabe mais um conhecimento restrito aos limites da universidade. A comunicação com o seu entorno é essencial, tanto para o aperfeiçoamento do estudante, como para o desenvolvimento local, já que a visão coletiva precisa ser sustentada na busca pelo bem-comum, uma vez que o sistema jurídico tem aporte nos anseios da sociedade, especialmente, no que tange a pacificação social. Assim:

imprescindível que o conhecimento gerado no âmbito do curso de direito não tenha como destino apenas o público interno, sem a preocupação de sua efetiva aplicação prática na sociedade, ou seja, já não é suficiente que o conhecimento gerado seja universitário, sendo necessária uma transição para um conhecimento ‘pluriversitário’ (OLIVEIRA; SERVA; DIAS, 2018, p. 326-340). 
Desse modo, a partir de tais percepções referentes à extensão, e, considerando os reflexos introduzidos pela Resolução CNE/CES 5/2018, que inseriu as novas diretrizes para o curso de Direito, é possível identificar uma linha educacional mais dialógica, voltada à formação de um profissional atuante, proativo e inserido na realidade social. A própria ideia de cidadania atrelada ao exercício da função requer a efetivação de vias que possibilitem uma postura de integração social. Ademais, não se trata apenas de exercitar a prática profissional, pois para isso há espaços apropriados. $\mathrm{O}$ que se almeja com a previsão das atividades de extensão é a aproximação entre "a Universidade e a comunidade por meio da prestação de serviços que potencializam a conduta cooperativa, solidária e democrática" (SCHAEFER, SPENGLER, 2019, p. 103).

Ao se considerar o acesso qualitativo à justiça, e, com base nas especificidades próprias das formas adequadas de solucionar conflitos de interesses, é possível vislumbrar um caminho assaz produtivo nas atividades de extensão, já que essas se encontram calcadas nos aspectos da dimensão social da produção de conhecimento, o que possibilita a atuação acadêmica (e, posteriormente, profissional) conectada à realidade dos cidadãos. Os instrumentos autocompositivos, como a mediação e a conciliação, requerem posturas profissionais que reconheçam no jurisdicionados sujeitos equivalentes, necessitados de oportunidades de diálogo, e de serviços que ofertem mais do que respostas objetivas e superficiais.

Por tais aspectos, tem-se nas atividades de extensão uma complementariedade do que fora instituído pela Resolução CNE/CES n5/2018, que introduziu a obrigatoriedade de disciplinas de enfoque consensual nas matrizes curriculares dos cursos de Direito. A teoria situa o discente e o apresenta a um novo conhecimento - no caso, vias eficazes na solução ou no tratamento de conflitos; a prática possibilita o desenvolvimento de competência e habilidades, preparando para o cotidiano de trabalho, que não depende unicamente das disputas processuais; já a extensão, por sua vez, une os aspectos anteriores, integralizando o aluno aos contornos sociais que nem sempre condizem com sua realidade.

$\mathrm{Na}$ análise de Boaventura de Sousa Santos (20152015, p. 107), os cursos de Direito, “enquanto locais de circulação dos postulados da dogmática-jurídica, têm estado distantes das preocupações sociais e têm servido, em regra, para a formação de profissionais sem um maior comprometimento com os problemas sociais". Nesse sentido, as novas diretrizes que implementam as atividades de extensão nos cursos superiores agregam ao processo de 
aprendizagem jurídica uma perspectiva de afinidade aos anseios sociais. O acesso à justiça mais próximo ao cotidiano da sociedade não se perfaz unicamente pela existência de clínicas ou escritórios espalhados por bairros ou favelas (proximidade física), mas, sobretudo, pelo fortalecimento das relações humanas.

Efetivar o acesso à justiça qualitativo é também democratizar o Direito, o que requer profissionais jurídicos comprometidos com serviços que nem sempre culminam em decisões judiciais ou em procedimentos contenciosos. Para isso, um conjunto de estratégias, ações e atividades precisam ser fortalecidas na formação de juristas, para que o engajamento com posturas mais cidadãs, democráticas e humanitárias sejam uma constante na profissão. Destarte, com fulcro nas diretivas que reformulam a extensão, tem-se a amplificação de espaços propícios à consolidação de uma justiça de proximidade com a sociedade em prol de um acesso mais efetivo.

\section{CONCLUSÃO}

O campo da educação jurídica, nos últimos anos, tem apresentado uma série de modificações, impulsionadas, especialmente, pela já reconhecida crise no sistema de prestação jurisdicional brasileiro. Nesse aspecto, a reformulação das diretrizes de ensino tornou-se fundamental para que o direito de acesso à justiça fosse garantido, uma vez que fatores como a alta litigiosidade (judicialização excessiva dos conflitos de interesse) têm obstaculizado a aproximação do cidadão de serviços jurídicos qualitativos.

Ao que tange o acesso à justiça, importante destacar que a política pública direcionada ao tratamento adequado de conflitos no âmbito do Poder Judiciário (Resolução $\mathrm{n}^{\circ}$ 125/2010 do CNJ) trouxe uma diversidade de implicações, inclusive na área de ensino, culminando na obrigatoriedade de disciplinas com enfoque nas formas consensuais de solução de conflitos (Resolução CNE/CES 5/2018) nos cursos de Direito. De igual forma, inovações como as atuais diretrizes para o desenvolvimento da extensão na educação superior (Resolução CNE/CES 7/2018) surgem como potenciais vias para consubstancialização do profissional jurídico no cerne da sociedade, ou seja, que o jurista em formação esteja vinculado a uma prestação jurídica que, de fato, satisfaça o cidadão.

Assim, com a realização da presente pesquisa pode-se concluir que as diretrizes atuais que implementam as atividades de extensão nos cursos de educação superior do país 
representam canais de interconexão entre o âmbito de produção de conhecimento e a esfera social. Sob tal ótica, na seara do ensino jurídico, a extensão irrompe-se como um potencial espaço de aproximação entre juristas em formação e cidadãos necessitados de respostas para seus conflitos. Desse modo, a partir de um enfoque que reconhece o direito fundamental de acesso à justiça como um direito que transcende o simples acesso à jurisdição estatal, é possível vislumbrar nas atividades extensionistas rotas favoráveis à disseminação de práticas consensuais de solução de conflitos entre os futuros profissionais de Direito.

Nesse sentido, a autocomposição, como a mediação e a conciliação, requer um perfil profissional e atuante, que privilegie o diálogo, a alteridade, o respeito mútuo e a autonomia de decisão dos conflitantes, o que também é alentado nas práticas extensionistas desenvolvidas sob as orientações da normativa atual. Não cabe mais um ensino do Direito retido em um nicho formal e de aplicações unicamente técnicas. O jurista contemporâneo precisa estar alinhado às pretensões de uma sociedade diversa e complexa, que é volúvel e instável, e, portanto, necessita de serviços jurídicos que considerem suas especificidades, para que a justiça se faça efetiva.

\section{REFERÊNCIAS}

ANDREUCCI, Álvaro Gonçalves Antunes; MAILLART, Adriana Silva. O ensino jurídico e a formação crítica e criativa de professores: apontamentos sobre a historiografia da história do direito no Brasil. In: SILVEIRA, Vladimir Oliveira da; SANCHES, Samyra Haydêe Dal Farra Naspolini; COUTO, Mônica Bonetti (Org.). Educação Jurídica. São Paulo: Saraiva, 2013.

BRASIL. Conselho Nacional de Justiça. Resolução no 125, de 29 de novembro de 2010.

Dispõe sobre a Política Judiciária Nacional de tratamento adequado dos conflitos de interesses no âmbito do Poder Judiciário e dá outras providências. Disponível em:

http://www.cnj.jus.br/images/atos_normativos/resolucao/resolucao_125_29112010_11032016 162839.pdf. Acesso em 29 ago 2020.

BRASIL. Conselho Nacional De Educação. Resolução CNE/CES 5/2018. Institui as Diretrizes Curriculares Nacionais do Curso de Graduação em Direito e dá outras providências.

Disponível em: https://www.in.gov.br/materia/-

/asset_publisher/Kujrw0TZC2Mb/content/id/55640393/do1-2018-12-18-resolucao-n-5-de-17de-dezembro-de-2018-55640113. Acesso em 01 set 2020.

BRASIL. Conselho Nacional De Educação. Resolução CNE/CES 7/2018. Institui as Diretrizes para a Extensão na Educação Superior Brasileira e dá outras providências. 
Disponível em:

http://portal.mec.gov.br/index.php?option=com_docman\&view=download\&alias $=104251$ rces007-18\&category_slug=dezembro-2018-pdf\&Itemid=30192. Acesso em: 04 set 2020.

CALMON, Petronio. Fundamentos da mediação e da conciliação. 4. ed. Brasília, DF: Gazeta Jurídica, 2019.

CAPPELLETTI, Mauro; GARTH, Bryant. Acesso à justiça. Tradução de Ellen Gracie Northfleet. Porto Alegre: Fabris, 1988.

COSTA, Bárbara Silva; ROCHA, Leonel Severo. Educação jurídica e formação de profissionais do futuro. $1^{\text {a }}$ Ed. Curitiba: Appris, 2018.

DENARDI, Eveline Gonçalves; FLORÊNCIO FILHO, Marco Aurélio. A metodologia da pesquisa nos cursos de direito: uma análise crítica. Revista da Faculdade Mineira de Direito, v. 20, n. 40 (2017), 91-117.

GROSMAN, Claudia Frankel; MANDELBAUM, Helena Gurfinkel. Mediação no Judiciário: teoria na prática, prática na Teoria. São Paulo: Primavera Editorial, 2011.

MORAIS, José Luis Bolzan de; SPENGLER, Fabiana Marion. Mediação e arbitragem: Alternativas à jurisdição! $4^{a}$ Ed. rev. e atual. Com a Lei 13.140/2015 e a Lei 13.129/2015 que alterou a Lei 9.307/1996. Porto Alegre: Livraria do Advogado, 2019.

MORIN, Edgar. A articulação de saberes. In: MORIN, Edgar; ALMEIDA, Maria da Conceição de; CARVALHO, Edgar de Assis (Org.). Educação e complexidade: os sete saberes e outros anseios. $3^{\text {a }}$ Ed. São Paulo: Cortez, 2005.

NEDER, Gizlene. CERQUEIRA FILHO, Gisálio. Formação jurídica e história das Faculdades de Direito em Portugal e no Brasil. Direito em Movimento, Rio de Janeiro, v. 16, n. 2, p. 106-136, $2^{\circ}$ sem., 2018.

OLIVEIRA, Emerson Ademir de; SERVA, Fernanda Mesquita; DIAS, Jefferson Aparecido. Aprendizagem cooperativa, disposição física e metodologia no ensino jurídico. In: Revista de Direito Brasileira. São Paulo, v. 21, n. 8, p. 326-340, set./dez. 2018.

SANTOS, Boaventura de Sousa. Para uma revolução democrática da justiça. Coimbra: Almedina, 2015.

SCHAEFER, Rafaela Matos Peixoto. SPENGLER, Fabiana Marion. O papel social das universidades comunitárias enquanto terceiro no tratamento dos conflitos. Revista Jurídica Direito \& Paz. São Paulo. Ano XII, no 41, p. 91-107, 2019.

SERRES, Michel. Polegarzinha. Tradução Jorge Bastos. $3^{\text {a }}$ Ed. Rio de Janeiro: Bertrand Brasil, 2018.

SPENGLER, Fabiana Marion. Da jurisdição à mediação: por uma outra cultura no tratamento de conflitos. 2ª Ed. Ijuí: Editora Unijuí, 2016. 
SPENGLER, Fabiana Marion. Mediação: técnicas e estágios. $1^{\text {a }}$ Ed. Santa Cruz do Sul: Essere nel Mondo, 2017.

STANGHERLIN, Camila Silveira; SPENGLER, Fabiana Marion. A comunidade enquanto local propício ao exercício da empatia: políticas públicas para as soluções extrajudiciais de conflitos em âmbito comunitário. Scientia Iuris, Londrina, v. 22, n. 3, p. 74-87, nov. 2018.

STANGHERLIN, Camila Silveira; SPENGLER, Fabiana Marion. O poder judiciário e o mito grego do deus Cronos: a judicialização dos meios consensuais de solucionar conflitos e o monopólio de acesso à justiça. Anamorphosis - Revista internacional de Direito e Literatura, v. 5, n. 1, jan - jun, 2019.

TARTUCE, Fernanda. Mediação nos conflitos civis. Rio de Janeiro: Forense: São Paulo: Método, 2008. 